\title{
Biomarker and Clinical Trial Design Support for Disease-Modifying Therapies: Report of a Survey of the EU/US
}

\section{Alzheimer's Disease Task Force}

Jeffrey Cummings, MD, ScD (1), Nick Fox, MD (2), Bruno Vellas, MD (3), Paul Aisen, MD (4), Guogen Shan, PhD (5) for the EU/US Alzheimer' Disease Task Force

From the Cleveland Clinic Lou Ruvo Center for Brain Health, Las Vegas, NV, USA (1); Dementia Research Centre, Department of Neurodegenerative Disease, UCL Institute of Neurology, University College London, London, UK (2); Department of Geriatric Medicine, University Toulouse III, Toulouse, France (3); Alzheimer's Therapeutic Research Institute, University of Southern California, San Diego, CA, USA (4); Department of Environmental and Occupational Health, Epidemiology and Biostatistics Program, School of Community Health Sciences, University of Nevada Las Vegas, Las Vegas, NV, USA (5)

\author{
Address correspondence to: \\ Jeffrey Cummings, MD, ScD \\ Cleveland Clinic Lou Ruvo Center for Brain Health \\ 888 W Bonneville Ave \\ Las Vegas, NV, 89106 \\ USA
}

T: 702.483.6029 
F: 702.722 .6584

Email: cumminj@ccf.org

Running Title: EU/US Task Force Biomarker Survey

\section{Disclosures:}

IC has provided consultation to Abbvie, Acadia, Actinogen, Alzheon, Anavex, Avanir, Axovant, Boehinger-Ingelheim, Bracket, Dart, Eisai, Forum, GE Healthcare, Genentech, Intracellular Interventions, Lilly, Lundbeck, Medavante, Merck, Neurocog, Novartis, Orion, Otsuka, Pfizer, Piramal, QR, Roche, Suven, Sunovion, Takeda and Toyama pharmaceutical and assessment companies.

$\underline{\mathrm{NF}}$ consults for Eli Lilly, Novartis, Sanofi, Roche, and GlaxoSmithKline GSK.

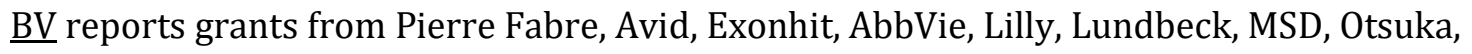
Regenron, Sanofi, Roche, AstraZeneca, LPG Systems, Nestlé, and Alzheon, and personal fees from Lilly, Lundbeck, MSD, Otsuka, Roche, Sanofi, Biogen, Nestlé, Transition Therapeutics, and Takeda.

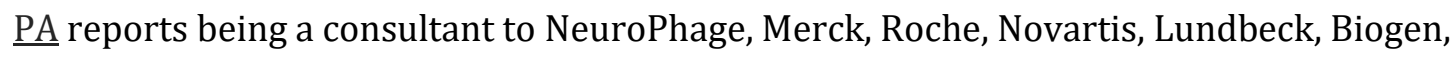
Probiodrug, Anavex, and Abbvie; and receiving grants from Eli Lilly and Company, Janssen, the Alzheimer's Association, and the NIH.

$\underline{\text { GS }}$ reports no conflicts of interest. 


\section{Abstract}

BACKGROUND: Disease-modifying therapies are urgently needed for the treatment of Alzheimer's disease (AD). The European Union/United States (EU/US) Task Force represents a broad range of stakeholders including biopharma industry personnel, academicians, and regulatory authorities. OBJECTIVES: The EU/US Task Force represents a community of knowledgeable individuals who can inform views of evidence supporting disease modification and the development of diseasemodifying therapies (DMTs). We queried their attitudes toward clinical trial design and biomarkers in support of DMTs.

DESIGN/SETTING/PARTICIANTS: A survey of members of the EU/US Alzheimer's Disease Task Force was conducted. Ninety-three members (87\%) responded. The details were analyzed to understand what clinical trial design and biomarker data support disease modification. MEASUREMENTS/RESULTS/CONCLUSIONS: Task Force members favored the parallel group design compared to delayed start or staggered withdrawal clinical trial designs to support disease modification. Amyloid biomarkers were regarded as providing mild support for disease modification while tau biomarkers were regarded as providing moderate support. Combinations of biomarkers, particularly combinations of tau and neurodegeneration, were regarded as providing moderate to marked support for disease modification and combinations of all three classes of biomarkers were regarded by a majority as providing marked support for disease modification. Task Force members considered that evidence derived from clinical trials and biomarkers supports clinical meaningfulness of an intervention, and when combined with a single clinical trial outcome, nearly all regarded the clinical trial design or biomarker evidence as supportive of disease modification. A minority considered biomarker evidence by itself as indicative of disease modification in prevention trials. Levels of evidence $(A, B, C)$ were constructed based on these observations. 
CONCLUSION: The survey indicates the view of knowledgeable stakeholders regarding evidence derived from clinical trial design and biomarkers in support of disease modification. Results of this survey can assist in designing clinical trials of DMTs.

Key words: Alzheimer's disease, clinical trials, biomarkers, EU/US Task Force 


\section{Biomarker and Clinical Trial Design Support for Disease-Modifying Therapies: Report of a Survey of the EU/US}

\section{Alzheimer's Disease Task Force}

Disease-modifying therapies (DMTs) for Alzheimer's disease (AD) are an increasingly important goal for drug development programs in an effort to prevent or delay the onset or slow the progression on the disease [1]. Analyses suggest that a delay of 5 years in the onset of AD by 2025 would decrease the frequency of the illness by $40 \%$ in 2035 and would save an estimated $\$ 367$ billion by $2050[2]$. A DMT can be defined as an intervention that produces an enduring change in the clinical progression of AD by interfering in the underlying pathophysiological mechanisms of the disease process leading to cell death $[3,4]$. Sources of data in support of disease modification (DM) include observations derived from trial designs and data from biomarkers collected in the course of clinical trials $[3,4]$.

To better understand how critical stakeholders view the strength of evidence used to support the concept of DM and to construct levels of evidence of DM, we conducted a survey of members of the European Union/United States (EU/US) Alzheimer's Disease Task Force including individuals with biopharma industry, academic, and regulatory backgrounds relevant to AD drug development. The Task Force has a history of convening, discussing, and recommending action for issues related to clinical trials in $\mathrm{AD}$ [5-9]. Based on the results of the survey we suggest levels of evidence for DMT clinical trials as ranked by Task Force members. The purpose of the survey and data organization/presentation is to assist those involved in DMT drug development to choose trial designs and biomarkers for trials that will best demonstrate DM.

\section{Research Methods}


The survey was conducted between June 26 and July 11, 2017 and consisted of 4 rounds of requests to all members of the EU/US Task Force to complete the survey. The purpose of the survey and the proposed use of the data collected were explained in the request soliciting the response. Ninety-three unique individuals responded to the survey of 107 active members of the Task Force for a response rate of $87 \%$.

Most of the questions (29/35) querying trial design and biomarker support for DMTs were framed as offering "no", "mild", "moderate”, or "marked” support for DM. Two participation questions, 3 demographic questions, and 3 yes/no questions were also posed. The survey reporting adheres to established guidelines[10]. Statistical comparisons used the_Bonferroni correction for multiple comparisons ( 6 possible combinations) within the question with an adjusted p-value of $0.05 / 6=0.0083($ PercD)

The survey was reviewed and a waiver for informed consent obtained from the Cleveland Clinic Institutional Review Board. All survey respondents agreed to take the survey and to have their responses used in a publication. All responses were anonymous. Not all respondents answered all questions; no questions had fewer than 70 respondents and most had 80 or more.

\section{Results}

The survey included demographic information regarding the participants. Of respondents, 48.91\% were members of the biopharma industry, $38.04 \%$ were primarily academicians with expertise in AD and DMT, and $13.04 \%$ were from other sectors including regulatory authorities. Of the participating Task Force members, $30.34 \% \%$ were active primarily in the EU, $55.43 \% \%$ in North America, and $14.13 \%$ in other world regions.

Data were collected on the experience of those responding to the survey; $6.59 \%$ were relatively new to drug development with $0-5$ years of experience, $10.99 \%$ had $6-10 y e a r s, 16.48 \%$ had $11-15$ years, $21.98 \%$ in $16-20$ years, and $43.96 \%$ had more than 20years of drug development 
experience. Cumulatively the respondents had a minimum of 1478.1 years of experience with clinical trials and drug development and more than $80 \%$ had at least 10 years of drug development experience.

The survey queried the respondents on the strength of data offered by types of trial design

for DM (Table 1). Staggered start and delayed withdrawal designs have been proposed as means of supporting DM [11-13]. Of the respondents, 10.71\%, 33.33\%, 36.90\% and 19.05\% thought the delayed start design with failure to catch up to the group treated first by the group treated after a delay offered no, mild, moderate, and marked support, respectively. The percentage difference (PercD) between mild and no support was $22.62 \%$ with a $95 \%$ confidence interval (CI) of $9.28 \%$ $35.96 \%$, and the PercD between moderate and no support was $26.19 \%$ with a $95 \%$ CI of $12.53 \%$ $39.84 \%$. Similarly, $9.88 \%, 41.98 \%, 32.10 \%$, and $16.05 \%$ of the respondents thought that the failure to fall to baseline levels by the withdrawn group in the delayed withdrawal design offered no, mild, moderate, and marked support for DM. A parallel group design with a drug-placebo difference at trial conclusion was considered to offer no support for DM by $32.94 \%$; mild support by $17.65 \%$, moderate support by $16.47 \%$, and marked support by $32.94 \%$.

\section{Table 1. Ratings of clinical trial design evidence in support of disease-modification.}

The survey queried observations regarding the slope of decline expected with DMTs. A change in slope of decline was considered to offer no, mild, moderate, and marked support for DM by $10.47 \%, 24.42 \%, 38.37 \%$, and $26.74 \%$ of the respondents. An increasing drug-placebo difference over time was thought to offer no, mild, moderate, and marked support for DM by $9.30 \%$, $19.77 \%, 34.88 \%$, and $36.05 \%$ of respondents. Delay to milestone observations (e.g, delay to reach Clinical Dementia Rating (CDR) scores of 1.0 from a CDR of 0.5 at baseline) were regarded as 
supporting no, mild, moderate, and marked support of DM by 19.77\%, 29.07\%, 36.05\%, and $15.12 \%$ of survey respondents.

The survey interrogated the support offered for DM by commonly used biomarkers including amyloid and tau imaging and cerebrospinal fluid (CSF) measures of amyloid beta protein 1-42 (Aß), total tau, and phospho-tau (p-tau) (Table 2). Reduction in amyloid burden as shown by amyloid imaging was regarded as offering no, mild, moderate, and marked support by $6.25 \%$, $52.50 \%, 30.00 \%$, and $11.25 \%$ of respondents (mild support VS no support: PercD $=46.25 \%, 95 \%$ $\mathrm{CI}=32.86 \%$ - 59.64\%; mild support VS marked support: $\mathrm{PercD}=41.25 \%, 95 \% \mathrm{CI}=26.27 \%-56.23 \%$ ). CSF measures of Aß were regarded similarly (20.25\%, 49.37\%. 24.05\%, 6.33\%).

Changes in tau imaging were regarded as indicative of DM by many respondents $(7.69 \%$, $26.92 \%, 46.15 \%, 19.23 \%$ considered reduction of tau burden on tau imaging as offering no, mild, moderate, and marked support for DM). Drug-placebo differences in total tau and p-tau were considered to offer similar levels of support for DM. Differences in CSF total tau were considered by $9.09 \%, 54.55 \%, 28.57 \%$, and $7.70 \%$ of respondents to offer no, mild, moderate and marked support for DM. For p-tau, 7.69\%, 50.00\%, 32.05\%, and 10.26\% considered drug-placebo difference to be indicative of no, mild, moderate, and marked support for DM.

Drug-placebo differences in fluorodeoxyglucose (FDG) positron emission tomography (PET) were considered by $16.46 \%, 41.77 \%, 31.65 \%$, and $10.13 \%$ of respondents to be indicative of DM. Individuals thought changes in volumetric magnetic resonance imaging (MRI) supported the occurrence of DM more than drug-placebo differences in functional MRI. Of the respondents, 7.69\%, 35.90\%, 38.46\%, and 17.95\% thought drug-placebo differences in MRI to offer no, mild, moderate, and marked support for DM. Drug-placebo differences in MRI were generally considered less indicative of DM $(22.08 \%, 51.95 \%, 20.78 \%$, and 5.19\% considered fMRI differences between drug and placebo to indicate no, mild, moderate, and marked support for DM). 
Table 2. Ratings of biomarker evidence in support of disease-modification.

The survey also queried the combinations of biomarkers that might be supportive of DM by a potential DMT. When considering drug-placebo differences on two amyloid biomarkers (e.g, amyloid imaging and CSF Aß), 7.59\%, 36.71\%, 36.71\%, and 18.99\% ranked the changes as offering no, mild, moderate, and marked support for DM). This compares to drug-placebo differences in two tau-related measures (e.g, tau imaging and CSF tau or p-tau) that was seen by $7.79 \%, 20.78 \%$, $49.35 \%$, and $22.08 \%$ of respondents as supportive of DM. The percentage of moderate support is significantly higher than that of no support (PercD=41.56\%, 95\% CI=27.45\% - 55.66\%), mild support $(\mathrm{PercD}=28.57 \%, 95 \% \mathrm{CI}=10.99 \%$ - 46.15\%), and marked support $(\mathrm{PercD}=27.27 \%, 95 \%$ $\mathrm{CI}=9.41 \%-45.14 \%$ ). Drug-placebo differences of combinations of amyloid-related plus tau-related measures were considered more indicative of DM: 5.33\%, $12.00 \%, 49.33 \%$, and $33.33 \%$ regarded the combination as indicating no, mild, moderate, and marked support. The percentage of moderate support or marked support is statistically significantly greater than that of no support or mild support. Therapies that produce changes in amyloid measures and volumetric MRI were considered by $2.56 \%, 11.54 \%, 53.85 \%$, and $32.05 \%$ as indicative of no, mild, moderate, or marked support of DM. Drug-placebo differences on the combination of volumetric MRI and measures of tau was regarded by $2.53 \%, 6.33 \%, 48.10 \%$, and $43.04 \%$ of respondents as indicative of DM. Drugplacebo differences on the combination of all three types of measures (amyloid, tau, MRI) was most likely to be seen by the respondents as supportive of DM: $2.53 \%, 6.33 \%, 30.38 \%$, and $60.76 \%$ thought this combination to support DM. The percentage of marked support is significantly greater than that of no support $(\operatorname{PercD}=58.22 \%, 95 \% \mathrm{CI}=46.27 \%-70.18 \%)$, mild support $(\mathrm{PercD}=54.43 \%$, 95\% CI=40.93\% - 67.93\%), and moderate support (PercD $=30.38 \%, 95 \% \mathrm{CI}=10.42 \%-50.34 \%)$.

The survey also sought to understand respondents' views of biomarkers using the Amyloid (A), Tau (T), and Neurodegeneration (N) classification of biomarkers [14]. Drug-placebo 
differences in A were regarded as indicative of DM by 7.79\%, 55.84\%, 29.87\%, and 6.49\% (no, mild, moderate, marked) of respondents. Drug-placebo differences in T were regarded as indicative of DM by 5.19\%, 35.06\%, 50.65\%, and 9.09\% of respondents. Drug-placebo differences in N were perceived as indicative of DM by $2.67 \%, 34.67 \%, 41.33 \%$, and $21.33 \%$ of respondents.

The survey also approached drug-placebo differences in combinations of biomarkers using the A, T, N approach. Drug-placebo difference in A plus T were regarded as indicative of DM by $4.00 \%, 20.00 \%, 53.33 \%$, and $22.67 \%$ of respondents. Differences in A plus N were perceived as supporting DM by $1.35 \%, 17.57 \%, 54.05 \%$, and $27.03 \%$ of surveyed individuals. Of respondents, $1.32 \%, 15.79 \%, 42.11 \%$, and $40.79 \%$ thought drug-placebo differences on T plus N to indicate DM. Drug-placebo differences on the combination of all three biomarker classes --- A, T, N --- were considered by $1.32 \%, 6.58 \%, 26.32 \%$, and $65.79 \%$ to support DM.

Table 3. Rating of biomarker Evidence of Disease-Modification using the A, T, N approach (A amyloid biomarkers, $\mathrm{T}$ - tau biomarkers, $\mathrm{N}$ - neurodegeneration biomarkers)

The survey queried respondents on how biomarker and clinical trial design observations related to other types of data in establishing clinical meaningfulness (Figure 1). Respondents were asked whether they thought evidence of DM (from trial designs or biomarkers) supported the concept of clinical meaningfulness of an intervention. Two-thirds (67.53\%) said "yes" (Figure 1a). Respondents were asked if evidence of DM (from trial designs or biomarkers) support clinical meaningfulness of an intervention if paired with a positive clinical outcome (e.g, AD Assessment Scale-cog subscale, CDR- sum of boxes, Preclinical Alzheimer Cognitive Composite, etc) in a trial of a DMT. Ninety percent (90.67\%) responded "yes" to this probe (Figure 1b). Considering the role of biomarkers in prevention trials, respondents were asked if biomarker evidence of successful intervention in the fundamental process of cell death could serve as a single primary outcome in 
prevention trials of participants with normal cognition and biomarker evidence of AD pathology. Approximately 40 percent (42.11\%) said “yes” (Figure 1c).

Figure 1a,b,c. Percent of respondents with "yes" and "no" answers to each of the probe question.

\section{Discussion}

Observations from this survey reflect the opinions of a majority of members of the EU/US Alzheimer's Disease Task Force. Together the respondents represent in excess of 1000 cumulative years of drug development experience. The survey specifically focused on the roles of clinical trial design and of biomarkers in supporting DM in clinical trials of AD DMTs. The survey also queried the roles of trial designs and biomarkers in regulatory discussions of clinical meaningfulness.

Delayed start and staggered withdrawal designs are frequently discussed as means of showing DM in clinical trials [3, 11-13]. There was some ambiguity in the responses obtained for trial design. Although, a minority of EU/EU Task Force members considered these designs as offering marked support for DM (19.05\% and 16.05\% respectively) and parallel group designs showing a drug-placebo difference at trial termination were seen as offering marked support for DM 32.94\%, the three trial designs had very similar percentages when moderate and marked support were combined (55.95\% for delayed start; $48.15 \%$ for staggered withdrawal; $49.41 \%$ for parallel group). A drug-placebo difference at trial termination in a parallel group trial was regarded as showing marked support or no support for DM by exactly equal numbers of Task Force members (32.94\% and $32.94 \%)$.

A number of secondary observations have been suggested as supportive of DM[3, 4]. When considering moderate and marked support together, a majority of Task Force members thought that a change in slope of decline and an increasing drug-placebo difference over time offered 
substantial support for DM (65.11\% and 70.93\%). Delay-to-milestone observations were thought to provide mostly mild (29.07\%) and moderate (36.05\%) support for DM.

Reductions in amyloid on amyloid imaging and drug-placebo differences in CSF Aß were considered to provide marked support for DM by a minority of Task Force members $111.25 \%$ for amyloid imaging, $6.33 \%$ for $\operatorname{CSF} A ß$, and $6.49 \%$ for $A$ in the $A, T, N$ classification). These measures were thought to offer moderate support by $30.00 \%, 24.05 \%$, and $29.87 \%$.

Tau imaging was perceived as providing stronger evidence of DM than amyloid imaging. Of the respondents, $19.23 \%$ thought tau imaging offered marked support for DM and $46.15 \%$ thought it offered moderate support (65.38\% together). CSF measures of tau were regarded less confidently as supporting DM; total tau was seen as offering marked and moderate support by $7.79 \%$ and $28.57 \%$, while p-tau was perceived as offering marked and moderate support by $10.26 \%$ and $32.05 \%$. Drug-placebo differences in $\mathrm{T}$ of the $\mathrm{A}, \mathrm{T}, \mathrm{N}$ classification were considered to offer marked and moderate support for DM by $9.09 \%$ and $50.65 \%$ (59.74\% together).

Drug-placebo difference on volumetric MRI was considered more supportive of DM than either amyloid or tau measures; $17.95 \%$ thought if offered marked support for DM and 38.46\% thought is moderately supportive (56.41\% together). Drug-placebo differences on $\mathrm{N}$ of the A, T, N classification were perceived as offering marked and moderate support by $21.33 \%$ and $41.33 \%$ (62.66\% together). Drug-placebo difference on FDG PET and fMRI were most commonly considered mildly supportive of DM (41.77\%, 51.95\%).

Drug-placebo differences on a combination of two types of amyloid biomarkers were considered somewhat supportive of DM (18.99\% marked support, 36.71\% moderate support). Drug-placebo difference on two types of tau biomarkers changed little from the confidence in DM derived from tau imaging by itself (22.08\% marked and $49.35 \%$ moderate support for the combination; $19.23 \%$ marked and $46.15 \%$ moderate for tau imaging by itself). Drug-placebo differences in combinations of biomarkers assessing different pathologies were perceived as 
supporting DM more strongly than individual or combinations of biomarkers measuring a single category of pathological change. Amyloid plus tau provided marked support for $33.33 \%$ of Task Force members and $49.33 \%$ thought it provided moderate support (81.69\% together); for amyloid plus MRI changes $32.05 \%$ and $53.85 \%$ thought the combination provided marked and moderate support (85.90\% together); for tau plus MRI 44.04\% and $48.10 \%$ thought the combination provided marked and moderate support (91.14\% together). Drug-placebo difference on the combination of all three types of biomarkers was thought to be most supportive of DM $(60.67 \%$ marked support). Overall, the trend was to regard the combination of biomarkers to be more indicative of DM than any single biomarker and confidence in DM increased with the number of biomarkers demonstrating a drug-placebo difference.

The A, T, N approach yielded results similar to the biomarker-specific approach (for marked support: $\mathrm{A}+\mathrm{T}=22.67 \% ; \mathrm{A}+\mathrm{N}=27.03 \% ; \mathrm{T}+\mathrm{N}=40.79 \%$ and $\mathrm{A}+\mathrm{T}+\mathrm{N}=65.79 \%)$. The concordance between the biomarker-specific rankings and the A, T, N rankings supports the internal validity of the survey.

Most Task Force members considered trial and biomarker evidence of DM to be clinically meaningful (67.53\%). A substantial majority (90.67\%) thought that the combination of a clinical measure (ADAS-cog, CDR-sb, PACC) plus trial design as biomarker evidence of DM would support the clinical meaningfulness of an intervention. A minority of Task Force members $(42.11 \%)$ thought that biomarker evidence of DM would serve as a single primary outcome in prevention trials.

Limitations of the survey include the relatively small size of the Task Force; the fact that not all respondents answered all questions; the possible ambiguity or misinterpretation of some questions; and possible subjective variability in defining "mild", "moderate", and "marked". 
Strengths include the experience of the stake holders; the high rate of response among Task Force members; and the internal consistency shown across the two biomarker classification systems used.

One of the goals of the survey was to allow construction of levels of evidence in support of DM to assist in guiding planning of trials of DMTs. Table 4 shows how the survey would guide the assignment of levels of evidence supportive of DM. Based on the percent of Task Force members indicating that a trial design or biomarker had marked, moderate or mild support for DM, the survey indicates that the trial design most commonly chosen to support DM was the parallel group approach (Class A); delayed start and delay-to-milestone designs offered moderate support (Class B); and staggered withdrawal designs offered mild support (Class C). Class A biomarker support for DM was based on the combination of $A+T+N$; Class B evidence included $T+N, A+N, A+T$, two $T$, two A, volumetric MRI, and tau imaging; Class C evidence included FDG, fMRI, CSF tau, CSF p-tau, CSF Aß, and amyloid imaging.

Table 4. Levels of evidence in support of DM as derived from the survey of the EU/US Alzheimer's Disease Task Force. In each case, the hierarchy is derived from the survey by which observation had marked support (Level A), moderate support (Level B), or mild support (Level C).

\section{Summary}

This survey of EU/US Alzheimer's Disease Task Force members provides insight into the opinions of those experienced with development of DMTs for AD. Cumulatively the respondents had nearly 1500 years of drug development experience. Some clear trends were evident in the survey such as the perception that drug-placebo differences in several types of biomarkers offers more support for DM than combinations of any two or any single biomarker. The survey allowed 
the construction of classes of evidence in support of DM (Table 4). The survey was designed to assist those involved in development of DMTs for AD to choose designs and biomarkers perceived by the stakeholders as indicative of DM. These observations may assist in constructing trials and marshalling evidence of DM in trials of urgently needed DMT for AD.

\section{Funding}

JC acknowledges support of a COBRE grant from the NIH/NIGMS (P20GM109025) and Keep Memory Alive.

\section{EU/US Task Force members who agreed to be acknowledged:}

Cosma-Roman D, Avanir Pharmaceuticals, USA; Dekosly S, University of Florida College of Medicine, USA; Delrieu J, CHU La Grave - Casselardit, France ; Donohue M, Keck School of Medicine, University of Southern California, USA; Dube S, Avanir Pharmaceuticals, USA ; Dubois B, Salpetriere Hospital, France; Frisoni G, IRCCS San Giovanni Dio, Italy; Fullerton T, Pfizer, USA; Gauthier S, McGill Center for Studies in Aging, Canada; Goedkoop R, Pharnext SA, France; Grundman M, Global R\&D Partners, USA; Guthrie S, UTHRIE Spencer, Prothena Biosciences, USA; Ho C, Denali Therapeutics, USA;

Tome M, European Medicines Agency, United Kingdom; Lawson J, Fujirebio, USA; Lovestone S, University of Oxford, United Kingdom; Lyketsos C, Johns Hopkins University, USA; Malamut R, Avanir Pharmaceuticals, USA ; Merdes A, Servier Forschung GmbH, Germany; Mintzer J, Roper St. Francis CBRT, USA; Molinuevo JL, ICN Hospital Clinic, Spain; Olsson T, Biogen, USA; Ousset PJ, CHU La Grave - Casselardit, France ; Peskind E, University of Washington School of Medicine, USA; Pollentier S, Boehringer Ingelheimer Pharma GmbH \& Co. KG, Germany; Porteinsson A, University of Rochester School of Medicine and Dentistry, USA; Pueyo M, Institut de Recherches Internationales SERVIER, France ; Rafii M, Keck School of Medicine, University of Southern California, USA; Raman R, Keck School of Medicine, University of Southern California, USA; 
Rosenberg P, John Hopkins University School of Medicine, USA; Rouru J, Orion Pharma, Finland;

Rubino I, Biogen, USA; Salloway S, Warren Alpert Medical School of Brown University, USA;

Scheltens P, VU University Medical Center, The Netherlands; Siemers E, Eli Lilly and Company, USA;

Siffert J, Nestlé Health Science, USA; Sims J, Eli Lilly and Company, USA; Smith J, Roche Products Ltd, United Kingdom; Sperling B, Biogen, USA; Sperling R, Harvard Medical School, USA; Touchon J, Jacques Touchon Conseil, France; Van der Geyten S, Janssen Research \& Development, Belgium; Weiner M, San Francisco Veterans Affairs Medical Center, USA; Wilcock G, University of Oxford, United Kingdom. 


\section{References}

1. Cummings J, Lee G, Mortsdorf T, Ritter A, Zhong K. Alzheimer's disease drug development pipeline: 2017. Alzheimer's \& Dementia: Translational Research \& Clinical Interventions 2017;3:367-384.

2. Alzheimer's Association. Changing the trajectory of Alzheimer's disease: how a treatment by 2025 saves lives and dollars. Chicago, IL: 2015.

3. Cummings JL, Fox N. Defining disease modification for Alzheimer's disease clinical trials. J Prev Alz Dis 2017;4:109-115.

4. Cummings JL. Disease modification and neuroprotection in neurodegenerative disorders. Transl Neurodegener 2017; In press.

5. Soto M, Abushakra S, Cummings J, et al. Progress in Treatment Development for Neuropsychiatric Symptoms in Alzheimer's Disease: Focus on Agitation and Aggression. A Report from the EU/US/CTAD Task Force. J Prev Alzheimers Dis 2015;2:184-188.

6. Vellas B, Aisen PS, Sampaio C, et al. Prevention trials in Alzheimer's disease: an EUUS task force report. Prog Neurobiol 2011;95:594-600.

7. Vellas B, Hampel H, Rouge-Bugat ME, et al. Alzheimer's disease therapeutic trials: EU/US Task Force report on recruitment, retention, and methodology. J Nutr Health Aging 2012;16:339-345.

8. Vellas B, Carrillo MC, Sampaio C, et al. Designing drug trials for Alzheimer's disease: what we have learned from the release of the phase III antibody trials: a report from the EU/US/CTAD Task Force. Alzheimers Dement 2013;9:438-444.

9. Vellas B, Bateman R, Blennow K, et al. Endpoints for Pre-Dementia AD Trials: A Report from the EU/US/CTAD Task Force. J Prev Alzheimers Dis 2015;2:128-135. 
10. Queensland Treasury. Presenting survey results, report writing. Queensland Government Statistician's Office, Australia: 2015.

11. Leber P. Observations and suggestions on antidementia drug development. Alzheimer Dis Assoc Disord 1996;10 Suppl 1:31-35.

12. Bodick N, Forette F, Hadler D, et al. Protocols to demonstrate slowing of Alzheimer disease progression. Position paper from the International Working Group on Harmonization of Dementia Drug Guidelines. The Disease Progression Sub-Group. Alzheimer Dis Assoc Disord 1997;11 Suppl 3:50-53.

13. Cummings JL. Defining and labeling disease-modifying treatments for Alzheimer's disease. Alzheimers Dement 2009;5:406-418.

14. Jack CR, Jr., Bennett DA, Blennow K, et al. A/T/N: An unbiased descriptive classification scheme for Alzheimer disease biomarkers. Neurology 2016;87:539-547. 
Table 1. Ratings of clinical trial design evidence in support of disease-modification.

\begin{tabular}{|l|l|l|l|l|}
\hline & No Support & Mild Support & $\begin{array}{l}\text { Moderate } \\
\text { Support }\end{array}$ & $\begin{array}{l}\text { Marked } \\
\text { Support }\end{array}$ \\
\hline $\begin{array}{l}\text { Delayed start design with failure } \\
\text { to catch up in delayed start } \\
\text { design }\end{array}$ & 10.71 & 33.33 & 36.90 & 19.05 \\
\hline $\begin{array}{l}\text { Staggered withdrawal design } \\
\text { with failure to fall back to } \\
\text { baseline levels in staggered } \\
\text { withdrawal design }\end{array}$ & 9.88 & 41.98 & 32.10 & 16.05 \\
\hline $\begin{array}{l}\text { Parallel group design with drug- } \\
\text { placebo difference at end of trial }\end{array}$ & 32.84 & 17.65 & 16.47 & 32.94 \\
\hline $\begin{array}{l}\text { Change in slope of decline in } \\
\text { active treatment group } \\
\text { compared to placebo }\end{array}$ & 10.47 & 24.42 & 38.37 & 26.74 \\
\hline $\begin{array}{l}\text { Increasing drug-placebo } \\
\text { divergence over time }\end{array}$ & 9.30 & 19.77 & 34.88 & 36.05 \\
\hline $\begin{array}{l}\text { Delay to milestones in the } \\
\text { course of the trial (e.g, } \\
\text { progression from CDR 0.5 to 1.) }\end{array}$ & 19.77 & 29.07 & 36.05 & 15.12 \\
\hline
\end{tabular}


Table 2. Ratings of biomarker evidence in support of disease-modification.

\begin{tabular}{|c|c|c|c|c|}
\hline & $\begin{array}{l}\text { No } \\
\text { Support }\end{array}$ & $\begin{array}{l}\text { Mild } \\
\text { Support }\end{array}$ & $\begin{array}{l}\text { Moderate } \\
\text { Support }\end{array}$ & $\begin{array}{l}\text { Marked } \\
\text { Support }\end{array}$ \\
\hline $\begin{array}{l}\text { Significant drug-placebo difference on } \\
\text { reduction of amyloid plaque burden on } \\
\text { amyloid imaging }\end{array}$ & 6.25 & 52.50 & 30.00 & 11.25 \\
\hline $\begin{array}{l}\text { Significant drug-placebo difference in } \\
\text { reduction of CSF } A \beta_{1-42}\end{array}$ & 20.25 & 49.37 & 24.05 & 6.33 \\
\hline $\begin{array}{l}\text { Significant drug-placebo difference on } \\
\text { reduction of tangle burden on tau imaging }\end{array}$ & 7.69 & 26.92 & 46.15 & 19.23 \\
\hline $\begin{array}{l}\text { Significant drug-placebo difference in change } \\
\text { in CSF total tau }\end{array}$ & 9.09 & 54.55 & 28.57 & 7.79 \\
\hline $\begin{array}{l}\text { Significant drug-placebo difference in change } \\
\text { in CSF phospho-tau }\end{array}$ & 7.69 & 50.00 & 32.05 & 10.26 \\
\hline $\begin{array}{l}\text { Significant drug-placebo difference in change } \\
\text { in FDG PET }\end{array}$ & 16.46 & 41.77 & 31.65 & 10.13 \\
\hline $\begin{array}{l}\text { Significant drug-placebo difference in change } \\
\text { in volumetric MRI }\end{array}$ & 7.69 & 35.90 & 38.46 & 17.95 \\
\hline $\begin{array}{l}\text { Significant drug-placebo difference in change } \\
\text { in functional MRI }\end{array}$ & 22.08 & 51.95 & 20.78 & 5.19 \\
\hline $\begin{array}{l}\text { Significant drug-placebo difference in two } \\
\text { amyloid markers such as amyloid imaging } \\
\text { and CSF } A \beta_{1-42}\end{array}$ & 7.59 & 36.71 & 36.71 & 18.99 \\
\hline $\begin{array}{l}\text { Significant drug-placebo difference in two } \\
\text { tau-related markers such as tau imaging and } \\
\text { CSF tau or p-tau }\end{array}$ & 7.79 & 20.78 & 49.35 & 22.08 \\
\hline $\begin{array}{l}\text { Significant drug-placebo difference in two } \\
\text { markers suggesting impact on amyloid AND } \\
\text { tau pathologies such as amyloid imaging or } \\
\text { CSF Aß1-42PLUS tau imaging for CSF tau/p-tau }\end{array}$ & 5.33 & 12.00 & 49.33 & 33.33 \\
\hline $\begin{array}{l}\text { Significant drug-placebo difference in two } \\
\text { markers suggesting impact on at amyloid } \\
\text { AND neurodegeneration such as amyloid } \\
\text { imaging or CSF A } \beta_{1-42} \text { PLUS MRI }\end{array}$ & 2.56 & 11.54 & 53.85 & 32.05 \\
\hline $\begin{array}{l}\text { Significant drug-placebo difference in two } \\
\text { markers suggesting impact on tau pathology } \\
\text { AND neurodegeneration such as tau imaging } \\
\text { or CSF tau/p-tau PLUS MRI }\end{array}$ & 2.53 & 6.33 & 48.10 & 43.04 \\
\hline $\begin{array}{l}\text { Significant drug-placebo difference in three } \\
\text { markers suggesting impact on tau AND } \\
\text { amyloid pathology AND neurodegeneration } \\
\text { such as amyloid imaging or CSF Aß1-42 PLUS } \\
\text { tau imaging or CSF tau/p-tau PLUS MRI }\end{array}$ & 2.53 & 6.33 & 30.38 & 60.76 \\
\hline
\end{tabular}


Table 3. Rating of biomarker Evidence of Disease-Modification using the A, T, N approach (A - amyloid biomarkers , $\mathrm{T}$ - tau biomarkers, $\mathrm{N}$ - neurodegeneration biomarkers )

\begin{tabular}{|l|l|l|l|l|}
\hline & No Support & Mild Support & $\begin{array}{l}\text { Moderate } \\
\text { Support }\end{array}$ & $\begin{array}{l}\text { Marked } \\
\text { Support }\end{array}$ \\
\hline $\begin{array}{l}\text { Significant drug-placebo } \\
\text { difference on A }\end{array}$ & 7.79 & 55.84 & 29.87 & 6.49 \\
\hline $\begin{array}{l}\text { Significant drug-placebo } \\
\text { difference on T }\end{array}$ & 5.19 & 35.06 & 50.65 & 9.09 \\
\hline $\begin{array}{l}\text { Significant drug-placebo } \\
\text { difference on N }\end{array}$ & 2.67 & 34.67 & 41.33 & 21.33 \\
\hline $\begin{array}{l}\text { Significant drug-placebo } \\
\text { difference on A PLUS T }\end{array}$ & 4.00 & 20.00 & 53.33 & 22.67 \\
\hline $\begin{array}{l}\text { Significant drug-placebo } \\
\text { difference on A PLUS N }\end{array}$ & 1.35 & 17.57 & 54.05 & 27.03 \\
\hline $\begin{array}{l}\text { Significant drug-placebo } \\
\text { difference on T PLUS N }\end{array}$ & 1.32 & 15.79 & 42.11 & 40.79 \\
\hline $\begin{array}{l}\text { Significant drug-placebo } \\
\text { difference on A PLUS T PLUS N }\end{array}$ & 1.32 & 6.85 & 26.32 & 65.79 \\
\hline
\end{tabular}


Table 4. Levels of evidence in support of DM as derived from the survey of the EU/US

Alzheimer's Disease Task Force. In each case, the hierarchy is derived from the survey by which observation had marked support (Level A), moderate support (Level B), or mild support (Level C).

\begin{tabular}{|l|l|l|}
\hline Level of Evidence & Type of Evidence & Specific Recommendation \\
\hline A & Clinical trial type & Parallel group design* \\
\hline B & Biomarker type & Drug-placebo differences in A+T+N \\
\hline & Clinical trial type & Delayed start or delay-to-milestone \\
\hline C & Biomarker type** & $\begin{array}{l}\text { T+N; A+N; A+T; two T; volumetric MRI; tau } \\
\text { imaging }\end{array}$ \\
\hline & Clinical trial type & Staggered withdrawal, \\
\hline Biomarker type & $\begin{array}{l}\text { FDG, fMRI, CSF tau, CSF p-tau, CSF Aß, } \\
\text { amyloid imaging }\end{array}$ \\
\hline
\end{tabular}

*Ambiguities concerning this recommendation are provided in the discussion.

**2 A biomarkers were equally ranked for moderate and mild support of DM.

$\mathrm{A}=$ amyloid, $\mathrm{T}=$ tau, $\mathrm{N}=$ neurodegeneration 


\section{Figure Legends}

Figure 1a,b,c. Percent of respondents with "yes" and "no" answers to each of the probe questions. 
Figure 1a. Percent of respondents with "yes" and "no" answers to the probe question.

Does evidence of disease-modification (from trial designs or biomarkers) support the concept of clinical meaningfulness of an intervention?

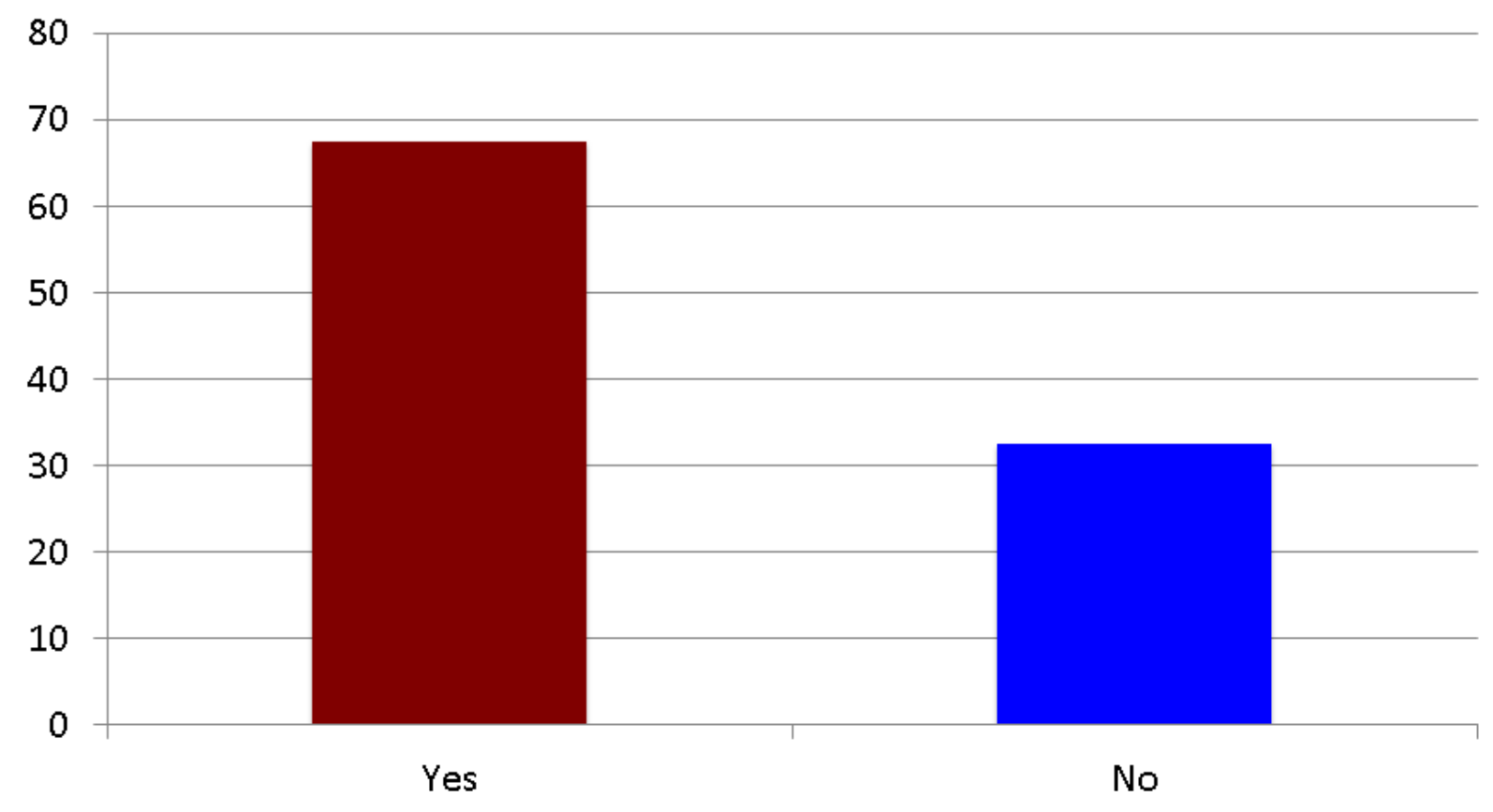


Figure 1b. Percent of the respondents with "yes" and "no" answers to the probe question.

Would evidence of disease-modification (from trial designs or biomarkers) support clinical meaningfulness of an intervention if paired with a clinical outcome in a trial of a disease-modifying agent?

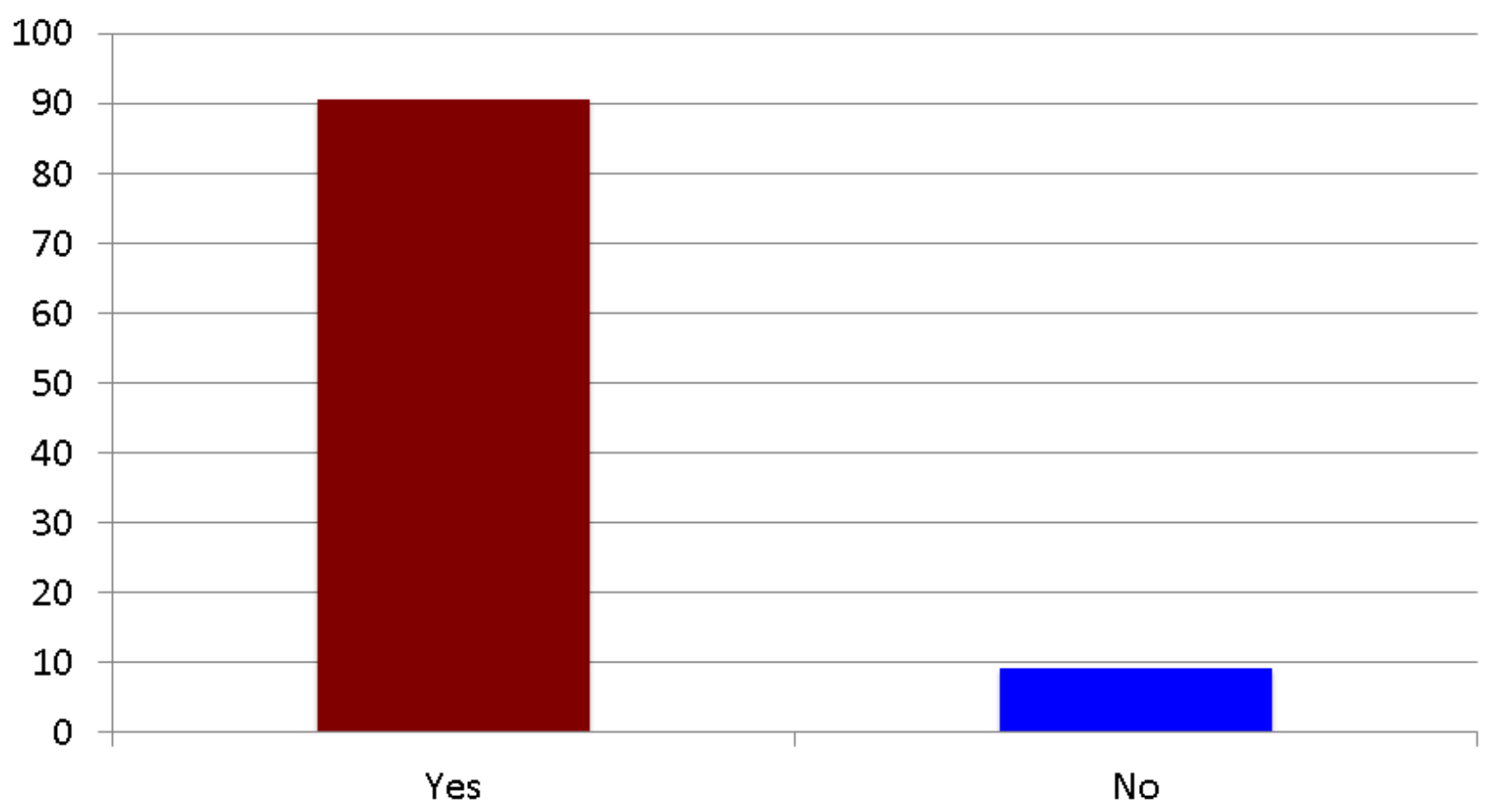


Figure 1c. Percent of the respondents with "yes" and "no" answers to the probe question.

\section{Could biomarker evidence of DM serve as a single primary} outcome in prevention trials?

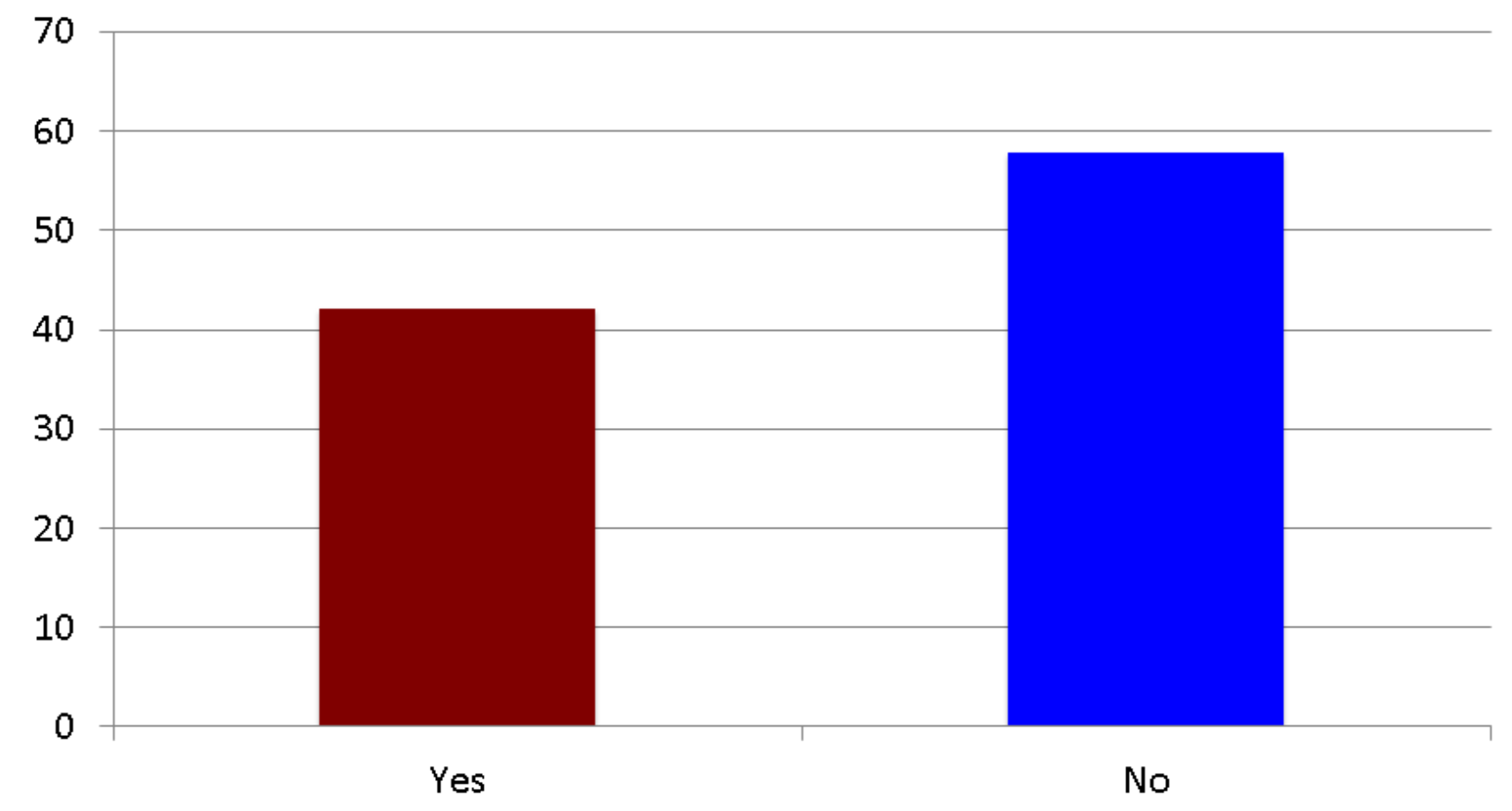

